\title{
Separation of BINAPO enantiomers on brush-type chiral stationary phases
}

\author{
Vladimir Vinković, ${ }^{a}$ Marin Roje, ${ }^{a}$ Darko Kontrec, ${ }^{a} *$ and Vitomir Šunjićc \\ ${ }^{a}$ Ruđer Bošković Institute, Bijenička 54, 10000 Zagreb, Croatia \\ ${ }^{b}$ Chirallica d.o.o., Bijenička 54, 10000 Zagreb, Croatia \\ E-mail: kontrec@irb.hr
}

Dedicated to Professor Arlette Solladié-Cavallo on her $70^{\text {th }}$ birthday

\begin{abstract}
Brush-type chiral stationary phase CSP 12 was specifically designed for separation of BINAPO enantiomers, which can be useful as organocatalysts or as chiral ligands in organometallic catalysis. This chromatographic separation process can compete with other routes to enantiomerically pure BINAPO.
\end{abstract}

Keywords: BINAPO, chiral stationary phase, brush-type, enantiomers, chiral chromatography

\section{Introduction}

Separation of enantiomers of axially chiral compounds is becoming an ever more important goal in chiral chromatography. The work in this field follows from the growing application of chiral compounds in the enantiomerically pure form as chiral organocatalysts or chiral ligands in organometallic catalytic complexes. ${ }^{1-4}$ Since chiral catalysis represents one of the most effective transfers of chirality in small and large-scale syntheses, ${ }^{5,6}$ any route to chiral organic molecules in the enantiopure form that can act as the catalyst, or be part of a catalytic system, is a worthwhile goal from an academic and industrial point of view.

Prompted by continuous reporting on new applications of chiral bidentate ligands, and by our interest in developing new brush-type chiral stationary phases (CSPs) for specific applications, ${ }^{7-11}$ we focused on the design and testing of a specific group of CSPs in order to perform chromatographic separation of BINAPO (1) enantiomers. So far in the literature the chromatographic enantioseparation of $\mathrm{BINAPO}^{12}$ or its fluoro derivatives ${ }^{13}$ is noted only for the purpose of the enantiomeric purity determination. There is a confusing use of acronym BINAPO in the literature. ${ }^{14-20}$ In some papers BINAPO refers to the mono-phosphine oxide of diphosphine derivative of binaphthyl (1A), ${ }^{14-16}$ in others to bis-phosphinite derivative (1B), ${ }^{17-19}$ and also to 
bis-phosphine oxide derivative (1). ${ }^{20-22}$ We are using acronym BINAPO only for the latter compound. This axially chiral diphosphine-oxide was first developed as an intermediate in one of the synthetic routes to the enantiomerically pure BINAP (2). ${ }^{23}$ Catalytic applications of $(+)$ and (-)-BINAP are numerous, beginning from enantioselective hydrogenation rearrangement of carbon skeletons. Nobel laureate Prof. R. Noyori has substantially contributed to the discovery and wide-scale application of BINAP. ${ }^{1,3}$

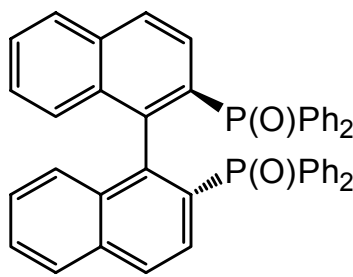

1<smiles>Pc1cc2ccccc2c(-c2c(P)ccc3ccccc23)c1-c1ccccc1</smiles>

$1 \mathrm{~A}$<smiles>Oc1ccc2ccccc2c1-c1c(OP)ccc2ccccc12</smiles>

1B<smiles></smiles>

2

Chromatographic separation of BINAPO enantiomers and their one-step reduction using silane, ${ }^{23}$ represent an effective route to the highly priced, optically pure BINAP enantiomers. $S$ BINAPO is acclaimed as starting material to prepare 5,5'-disubstituted $S$-BINAP congeners via bromination, cyanation and final hydrogenation of both cyano and phosphinoxide groups. ${ }^{24} \mathrm{~A}$ similar approach was reported where 5,5'-diamino $S$-BINAP is obtained starting from $S$ BINAPO. ${ }^{25}$ Soon after the first separation of BINAPO enantiomers, catalytic applications of this axially chiral bis-P-oxide were reported in production of chiral target compounds in the enantiomerically pure form. Thus $S$-BINAPO has been used as a chiral organocatalyst in enantioselective allylation of aldehydes with allyltrichlorosilane, ${ }^{20,21}$ in allylation of benzoylhydrazones, ${ }^{22}$ and in symmetric ring opening of meso-epoxides. ${ }^{26}$ The coordination chemistry of BINAPO has not been well explored. ${ }^{15,27}$ However catalytic activity of its organometallic complexes can be expected due to its high affinity for hard metal ions, as indicated by reductive coupling of ketones with $\alpha, \beta$-unsaturated esters promoted by the complex of BINAPO with $\mathrm{Sm}(\mathrm{II}) \mathrm{I}_{2}{ }^{28}$

Due to catalytic versatility of optically pure BINAPO and its intermediacy in the manufacture of BINAP, new effective methods for separation of racemic BINAPO are highly welcome. Based on our preliminary experience with chromatographic separation of BINAPO enantiomers, herein we report the synthesis and evaluation of novel CSPs for their large-scale separation.

\section{Results and Discussion}

We previously identified the CSP 1 as a promising separator of BINAPO enantiomers, ${ }^{7,8}$ as illustrated in Figure 1, for a $\mathrm{MeOH}$ - MTBE mixture as eluent. In spite of large difference in $\mathrm{R}_{\mathrm{t}}$ 
values of enantiomers, significant peak-broadening and the need for binary solvent mixture leave the space for improved separation capacity of new CSPs. Prompted by this result we decided to get more knowledge about structural segments of brush-type CSPs required for effective molecular recognition of BINAPO enantiomers, in order to prepare highly effective CSP for the large-scale, including SMB separation of BINAPO.

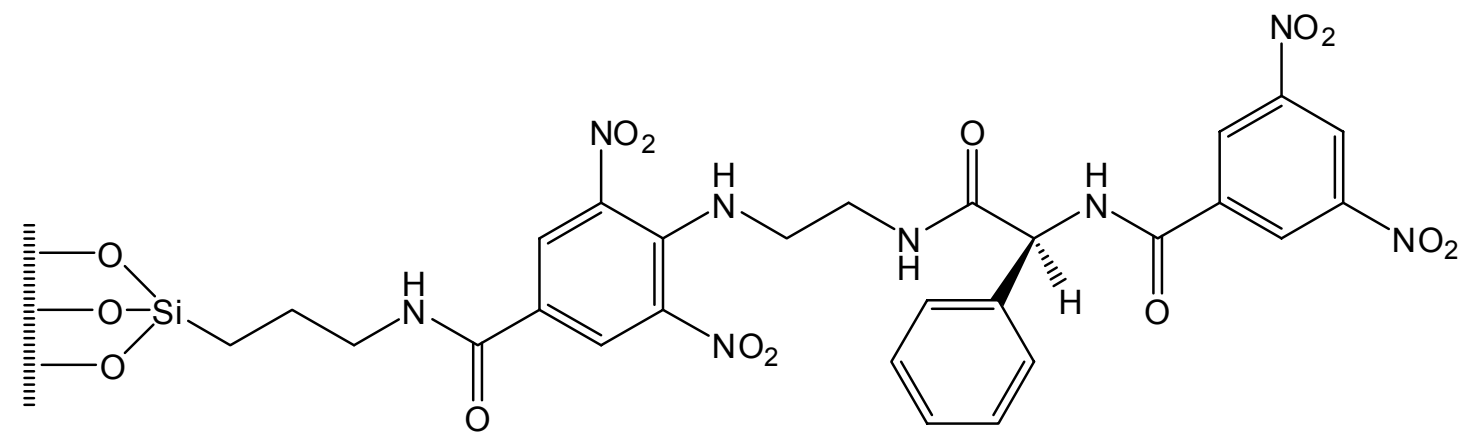

CSP 1

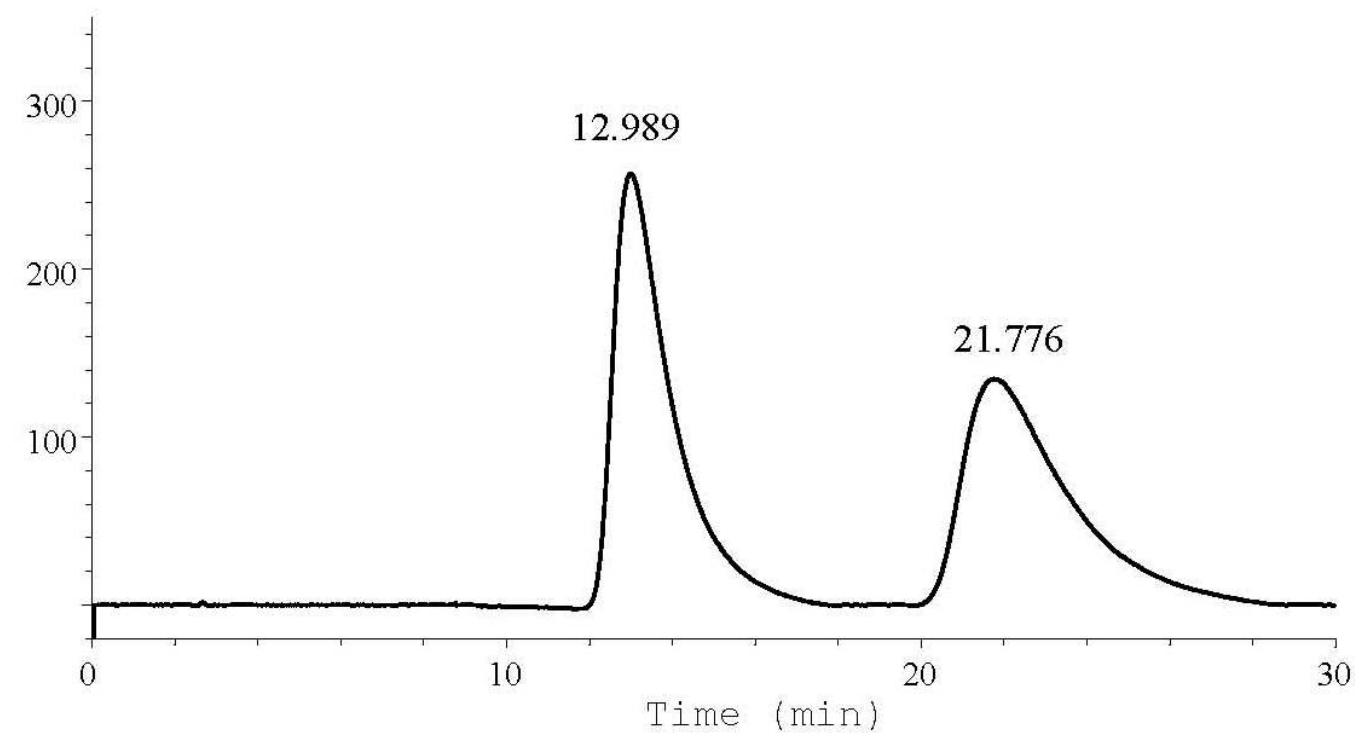

Figure 1. Chromatogram obtained for racemic BINAPO on CSP 1; column dimension $150 \mathrm{~mm}$ x $4.6 \mathrm{~mm}$ ID, mobile phase $n$-hexane - 2-propanol (50:50), flow rate $1.0 \mathrm{ml} / \mathrm{min}$.

BINAPO possess two oxygen atoms in the P-O bonds as good hydrogen-bond acceptors, while highly polarized resonance structures of BINAPO can be involved in the strong electrostatic interactions with the chiral selector. These properties qualify BINAPO as a good candidate for enantioseparation on the brush-type CSPs that can accommodate such a large $\mathrm{C}_{2}$ 
symmetric molecule and match both types of interactions. Indeed, inspection of the models of 1 in its skewed conformation and of the chiral separator unit within CSP 1 has revealed many possible mutual orientations that allow hydrogen bonding between some of the three amide $\mathrm{N}-\mathrm{H}$ bonds, one vinylogous amide $\mathrm{N}-\mathrm{H}$ in CSP 1, and one or both P-O oxygen atoms in BINAPO, as well as electrostatic interactions between $\mathrm{P}-\mathrm{O}$ and $\pi$-deficient aromatic DNB unit. It was intuitively concluded that not all interactions of BINAPO are contemporaneously possible along the CSP 1 backbone, and that properly designed new chiral selectors should contain less complex and more effective assembly of selected subunits.

Preparation of CSPs designed following this rationale is presented in Scheme 1.

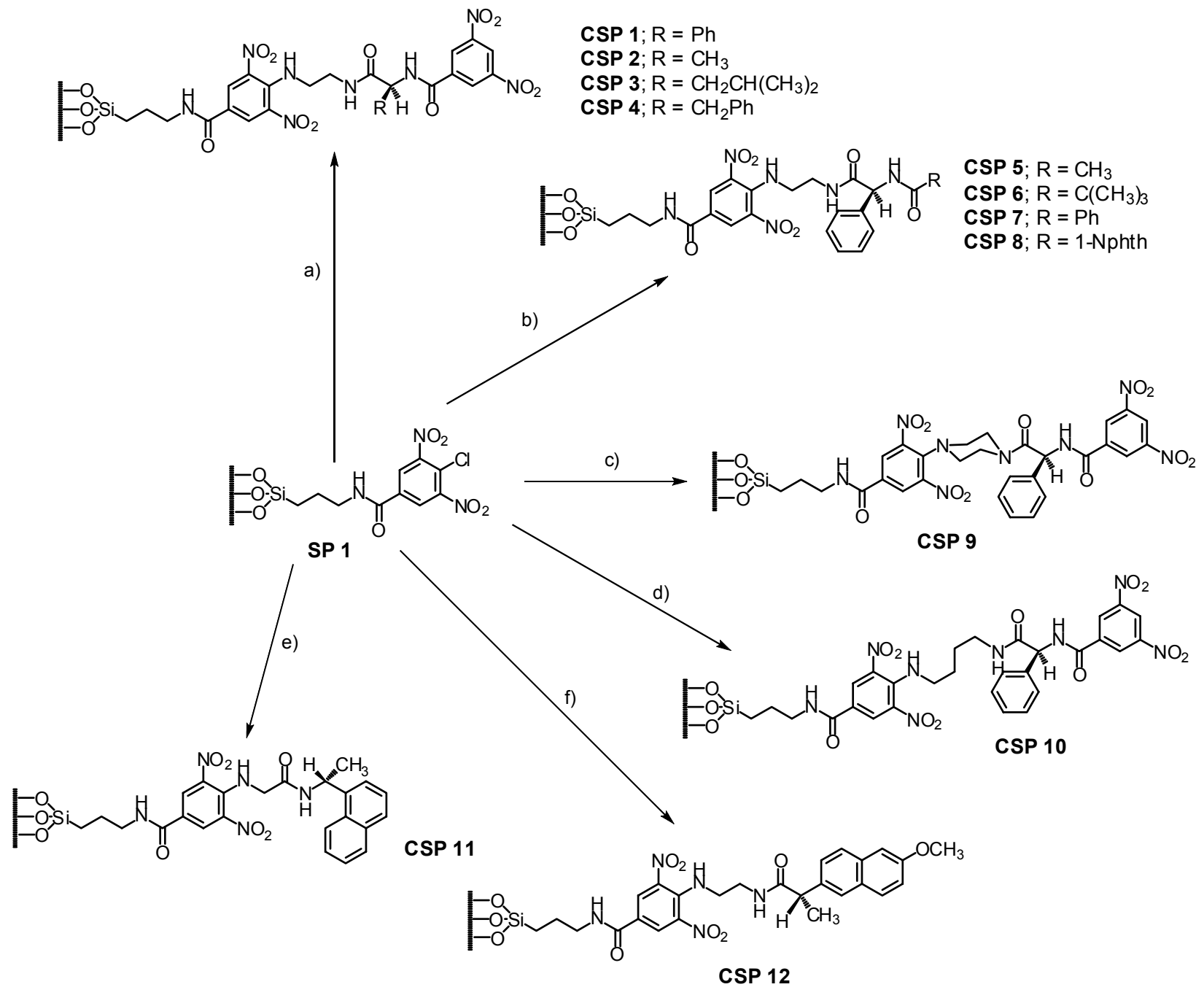

Scheme 1. Reagents and conditions. (a)1,2-diaminoethane, $\mathrm{CH}_{2} \mathrm{Cl}_{2}$, r.t.; $N$-DNB derivative of Lamino acid, EEDQ, THF, r.t.; (b) 1,2-diaminoethane, $\mathrm{CH}_{2} \mathrm{Cl}_{2}$, r.t.; $N$-DNB derivative of Lphenylglycine, EEDQ, THF, r.t.; (c) piperazine, $\mathrm{CH}_{2} \mathrm{Cl}_{2}$, r.t.; $N$-DNB-L-phenylglycine, EEDQ, THF, r.t.; (d) 1,4-diaminobutane, $\mathrm{CH}_{2} \mathrm{Cl}_{2}$, r.t.; $N$-DNB-L-phenylglycine, EEDQ, THF, r.t.; (e) (R)-(+)-2-amino-N-(1-naphthalen-1-yl-ethyl)-acetamide, $N$-ethyldiisopropylamine, THF, r.t.; (f) 1,2-diaminoethane, $\mathrm{CH}_{2} \mathrm{Cl}_{2}$, r.t.; (S)-(+)-6-methoxy-2-naphthyl-propionic acid, EEDQ, THF, r.t. 
The synthesis started from commercial aminopropyl silica gel which was acylated to the stationary phase SP 1 according to the published procedure. ${ }^{7}$ In the next steps insertion of the spacer to obtain intermediate SP 2 to SP 4, followed by introduction of chiral unit (separator) afforded CSP 1 to CSP 12. Reagents and conditions are listed in Scheme 1 for the different steps, while detailed protocols are given in the Experimental.

The testing of CSP 1 to CSP 4 in separation of BINAPO enantiomers has revealed crucial role of $\pi$-basic phenyl unit at stereogenic center in CSP 1 in enantiorecognition of BINAPO, since CSP 2 to CSP 4, derived from L-Ala, L-Leu and L-Phe, exhibit very low separation, Table 1 .

Table 1. Chromatographic results obtained for BINAPO by CSPs 1 to CSP 12 at $24{ }^{\circ} \mathrm{C}$ with 1 $\mathrm{ml} / \mathrm{min}$ as flow-rate

\begin{tabular}{|c|c|c|c|c|c|c|}
\hline & \multicolumn{3}{|c|}{ Mobile phase I* } & \multicolumn{3}{|c|}{ Mobile phase II** } \\
\hline & $\mathrm{k}_{1}$ & $\alpha$ & $\mathrm{R}_{\mathrm{S}}$ & $\mathrm{k}_{1}$ & $\alpha$ & $\mathrm{R}_{\mathrm{S}}$ \\
\hline CSP 1 & 5.18 & 1.81 & 2.34 & 4.75 & 1.92 & 4.41 \\
\hline CSP 2 & 3.42 & 1.03 & $\mathrm{~nm} * * *$ & 3.32 & 1.07 & 0.82 \\
\hline CSP 3 & 2.98 & 1 & - & 2.94 & 1 & - \\
\hline CSP 4 & 4.06 & 1.16 & 0.37 & 3.85 & 1.12 & 0.42 \\
\hline CSP 5 & 2.57 & 1.39 & 1.27 & 3.32 & 1.32 & 1.69 \\
\hline CSP 6 & 2.72 & 1.48 & 2.09 & 4.12 & 1.54 & 3.03 \\
\hline CSP 7 & 3.92 & 1.65 & 2.04 & 4.73 & 1.66 & 3.92 \\
\hline CSP 8 & 3.83 & 1.79 & 2.13 & 4.62 & 1.75 & 4.12 \\
\hline CSP 9 & 2.00 & 1.07 & $\mathrm{~nm} * * *$ & 2.78 & 1.10 & 0.44 \\
\hline CSP 10 & 4.67 & 1.72 & 2.16 & 4.96 & 1.75 & 3.88 \\
\hline CSP 11 & 7.00 & 1.23 & $\mathrm{~nm} * * *$ & 4.96 & 1.29 & 0.21 \\
\hline CSP 12 & 4.88 & 2.06 & 3.69 & 4.67 & 2.51 & 7.06 \\
\hline CSP 13 & 4.81 & 2.10 & 2.31 & 4.07 & 2.48 & 4.45 \\
\hline CSP 14 & 2.12 & 1.77 & 2.11 & 3.77 & 2.01 & 3.87 \\
\hline
\end{tabular}

*Mobile phase I $=n$-hexane - 2-propanol (7:3). **Mobile phase II = MTBE - methanol (9:1). $* * * \mathrm{~nm}=$ non-measurable, most often as a result of very broad peaks

Second set of CSPs (CSP 5 to CSP 8) was designed to examine the impact of the terminal group. These CSPs instead of strong $\pi$-acceptor 3,5-dinitrobenzoyl (DNB) group contain $\pi$-donor aromatic, phenyl or naphthyl, group (CSP 7 and CSP 8) or aliphatic, methyl or tert-butyl, group (CSP 5 and CSP 6). All four CSPs exhibit good separation of BINAPO enantiomers, suggesting that terminal $\pi$-acid group is not included in the interactions with BINAPO and can be safely eliminated from the structure of chiral selector. 
To test the effect of the flexibility of the aliphatic spacer, stationary phases CSP 9 and CSP 10 were prepared via SP 3 and SP 4. CSP 9 with longer n-butane spacer effects the enantioseparation of BINAPO with similar efficacy as CSP 1, revealing limited influence of that the length of spacer. To the contrary, CSP 10 that contain the more rigid, cyclic piperazine unit exhibit very low separation efficacy. Lost of efficacy of CSP 9 could be ascribed to the bulkiness of piperazine ring, and more probably to the absence of the terminal sec. amide group $\mathrm{H}-\mathrm{N}(\mathrm{CO})$ $\mathrm{R}$ to enter hydrogen bonding with BINAPO.

Assuming that not all four N-H amide protons in CSP 1 to CSP 8 and in CSP 10 can be engaged in hydrogen bonding, CSP 11 and CSP 12 are prepared. Both CSPs lack one amide unit as compared to CSP 1-4, and mutually differ in the orientation of the terminal amide group. Somewhat surprisingly, CSP 11 exhibited low separation capacity, but to our satisfaction CSP 12 proved most effective of all tested new CSPs, Table 1. It is of outmost practical importance that CSP 12 comprises $(S)-(+)-6-m e t h o x y p h e n y l$ propionic acid as chiral unit, an inexpensive, commercially available $\alpha$-aryl propionic acid, known anti-inflammatory agent under generic name Naproxen, frequently used as a source of chirality in various brush-type CSPs prepared from different authors. ${ }^{29-31}$ Huge difference in enantiorecognition capacity between CSP 11 and CSP 12 is demonstrated on the Figs. 2 and 3 for the selected binary solvent mixture.

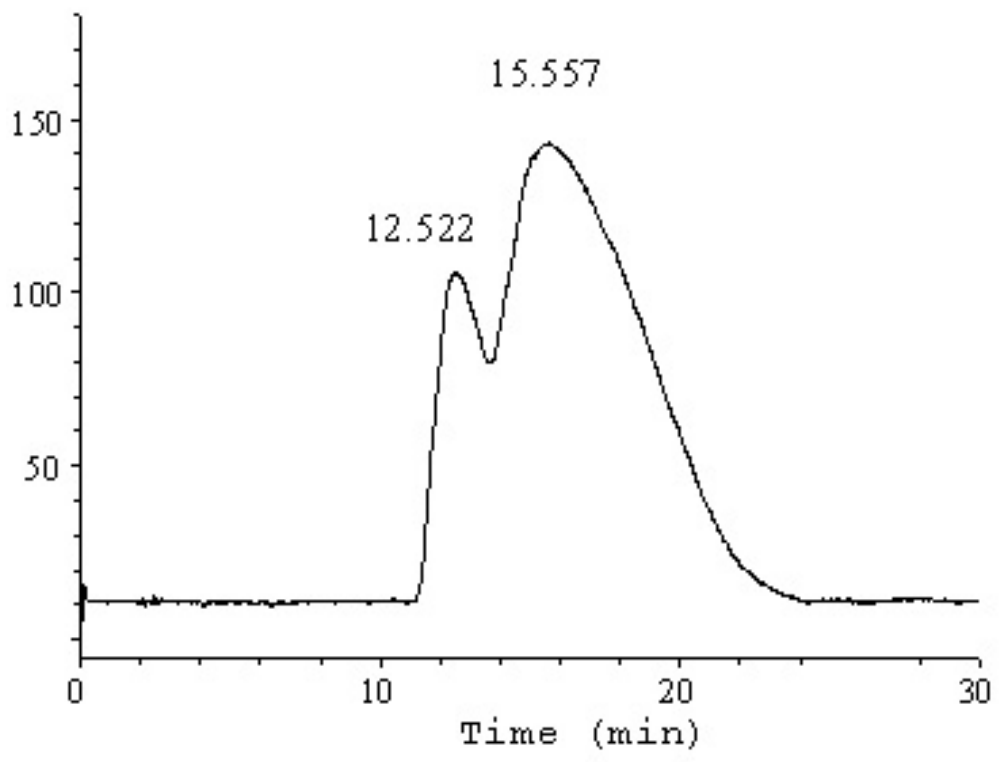

Figure 2. Chromatogram obtained for BINAPO on CSP 11; column dimension $150 \mathrm{~mm} \times 4.6$ $\mathrm{mm}$ ID; mobile phase MTBE - methanol (90:10), flow rate $1.0 \mathrm{ml} / \mathrm{min}$. 


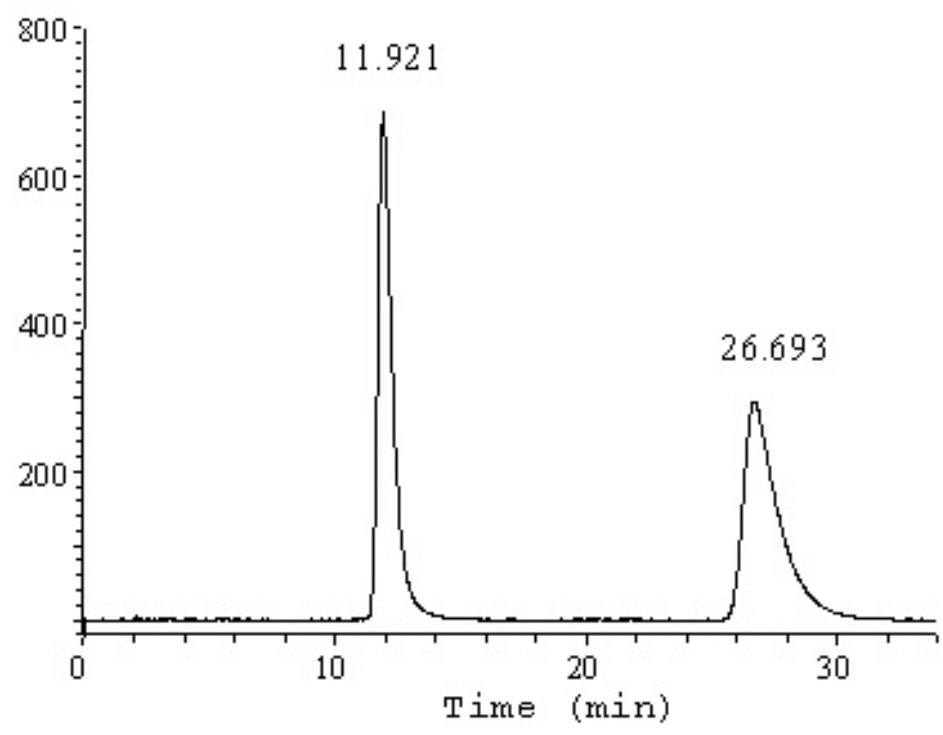

Figure 3. Chromatogram obtained for BINAPO on CSP 12; column dimension $150 \mathrm{~mm} \times 4.6$ $\mathrm{mm}$ ID; mobile phase MTBE - methanol (90:10), flow rate $1.0 \mathrm{ml} / \mathrm{min}$.

In the final attempts to improve separation efficacy of CSP $12 \pi$-acidic unit bound to $\gamma$ aminopropyl silica was varied. Two novel $\pi$-acidic aromatic units were build in the CSP 13 and CSP 14, Scheme 2, one of them with linear the other with angular position of the two alkylamino chains. The routes to CSP 13 and CSP 14 start from SP 5 and SP 7, via SP 6 and SP 8, respectively, applying similar reaction conditions as for CSPs in the Scheme 1. It deserves mentioning that in the CSP 14 an element of planar chirality is introduced, angularly alkylamino substituted aromatic ring, which corresponds to irregular triangle, simplex of the twodimensional space imaginable on the silica surface. ${ }^{32}$

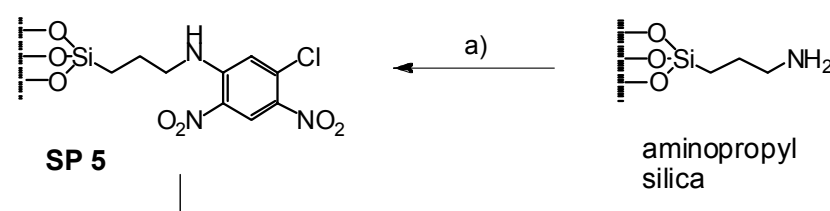

d)

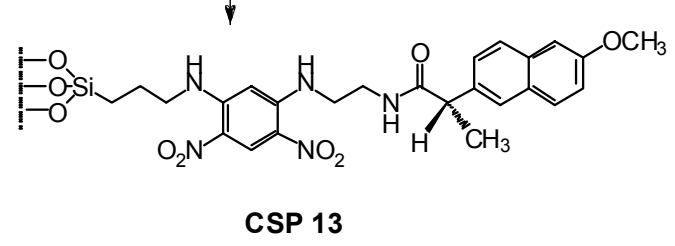

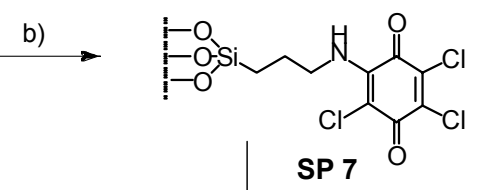

d)

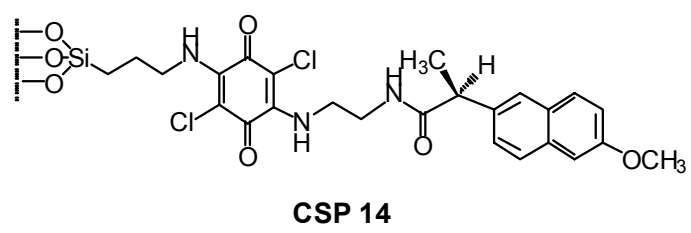

Scheme 2. Reagent and conditions. (a) 1,3-dichloro-4,6-dinitrobenzene, DMF, r.t.; (b) 2,3,5,6tetrachloro-[1,4]-benzoquinone, r.t.; (c) 1,2-diaminoethane, $\mathrm{CH}_{2} \mathrm{Cl}_{2}$, r.t.; $(S)$-(+)-6-methoxy-2naphtyl-propionic acid, EEDQ, THF, r.t.; (d) 1,2-diaminoethane, $\mathrm{CH}_{2} \mathrm{Cl}_{2}$, r.t.; $(S)-(+)-6$ methoxy-2-naphthyl-propionic acid, EEDQ, THF, r.t. 
Both CSPs exhibited similar profile of chromatographic parameters as CSP 12, Table 1, revealing that high degree of optimization of distance and orientation of interacting units with BINAPO, H-bond acceptors and donors and $\pi$-aromatic units is achieved with CSP 12 .

During this study the elution order of enantiomers was simultaneously checked by CD detector. On all CSPs that contain chiral unit derived from amino acids with $S$-absolute configuration, the elution order of BINAPO enantiomers was the same; $(+)$-enantiomer with $R$ absolute configuration $^{33}$ was eluted first and (-)-S-enantiomer was the second. Only on CSP 9, derived from L-phenylglycine with piperazine as a spacer, and on CSP 12, derived from $S$ naproxene, the elution order was reversed.

In conclusion, optimization of chiral stationary phases suitable for preparative separation of BINAPO enantiomers was performed. The exceptional enantioseparation $\left(\alpha=2.51, \mathrm{R}_{\mathrm{S}}=7.06\right)$ was achieved on CSP 12 derived from $S$-naproxen what affirmed this CSP as the chiral phase of choice for scale-up separation of BINAPO enantiomers. From the results obtained with this short series of CSPs it can be assumed that mechanism of chiral recognition of BINAPO include hydrogen bonding between one amide proton and one oxygen of BINAPO, and electrostatic interactions of $\pi$-deficient aromatic unit close to silica surface with second oxygen of BINAPO.

\section{Experimental Section}

General Procedures. Thin layer chromatography was performed on DC-Alufolien Kieselgel 60 $\mathrm{F}_{254}$ (Merck, Darmstadt, Germany) and the compounds were detected using Spectroline UV lamp at $254 \mathrm{~nm}$. Column chromatography was performed by using silica gel, particle size 0.063-0.200 mm (J. T. Baker, Deventer, Netherlands). Silica gel Separon SGX NH2 (Tessek, Prague, Czech Republic), particle size $5 \mu \mathrm{m}$ and pore size $100 \AA$, was used for the binding of chiral selectors. HPLC was performed with Knauer HPLC Pump 64 (Knauer, Berlin, Germany) equipped with 4Port Knauer Degasser, CD detector Jasco CD-2095 Plus permitting simultaneous UV and CD detection (Jasco, Tokyo, Japan), Interface Knauer, Solvent Saver VICI Jour Research Model 2909 (VICI Jour Research, Onsala, Sweden) and UV detector Knauer Variable Wavelength Monitor. The detection was achieved at $270 \mathrm{~nm}$ on both detectors. Integration of the chromatograms was made with Chromatography Software Management System EUROCHROM 2000 for Windows, Version 1.65, software package (Knauer, Berlin, Germany).

The packing of HPLC columns, purchased from Max Stevenson (Berlin, Germany), dimensions $150 \mathrm{~mm}$ x $4.6 \mathrm{~mm}$ I.D., was performed by slurry technique using Knauer pneumatic HPLCpump. $n$-Hexane, propan-2-ol, methanol and MTBE used for the chromatography and the packing of columns were of analytical grade (J. T. Baker) and redistilled before use. The HPLC column dead volume $\left(\mathrm{t}_{0}\right)$ was estimated by using 1,3,5-tri-tert-butylbenzene. Analyte samples were prepared by dissolving $2 \mathrm{mg}$ of the racemic BINAPO in $1 \mathrm{ml}$ of mobile phase. For analytical purposes $20 \mu \mathrm{l}$ of freshly prepared solution was used. On the basis of retention times of the enantiomers $\left(t_{R 1}\right.$ and $\left.t_{R 2}\right)$, the following chromatographic parameters were calculated: 
retention factor of the first eluted enantiomer $\mathrm{k}_{1}=\left(\mathrm{t}_{1}-\mathrm{t}_{0}\right) / \mathrm{t}_{0}$; retention factor of the second eluted enantiomer $\mathrm{k}_{2}=\left(\mathrm{t}_{1}-\mathrm{t}_{0}\right) / \mathrm{t}_{0}$; separation factor $\alpha=\mathrm{k}_{2} / \mathrm{k}_{1}$; resolution factor $\mathrm{R}_{\mathrm{S}}=2\left(\mathrm{t}_{2}-\mathrm{t}_{1}\right) /\left(\mathrm{w}_{1}+\mathrm{w}_{2}\right)$, where $\mathrm{w}$ is the baseline bandwidth obtained by drawing tangents to the inflexion points of the chromatographic peak.

\section{Preparation of stationary phases}

Synthesis of SP 1 and SP 2 was published previously. ${ }^{7,34}$

\section{SP 3}

The mixture of SP $1(3.0 \mathrm{~g})$, piperazine $(10 \mathrm{ml})$ and dichloromethane $(10 \mathrm{ml})$ was homogenized by sonification for $5 \mathrm{~min}$. The obtained suspension was stirred for $2 \mathrm{~h}$ at room temperature. Product was isolated by vacuum filtration on G-4 filter, washed with methanol (100 ml) and dried at $70{ }^{\circ} \mathrm{C}$ for $5 \mathrm{~h}$. It was obtained $2.99 \mathrm{~g}$ of SP 3. Anal. found: C 5.49, H 1.16, N $2.24 \%$. As calculated on $\mathrm{C} \%, 1.0 \mathrm{~g}$ of CSP contains $0.23 \mathrm{mmol}$ of bound organic material.

\section{SP 4}

The mixture of SP $1(3.0 \mathrm{~g}), 1,4-$ diaminobutane $(10 \mathrm{ml})$ and dichloromethane $(10 \mathrm{ml})$ was homogenized by sonification for $5 \mathrm{~min}$. The obtained suspension was stirred for $2 \mathrm{~h}$ at room temperature. Product was isolated by vacuum filtration on G-4 filter, washed with methanol (100 $\mathrm{ml}$ ) and dried at $70{ }^{\circ} \mathrm{C}$ for $5 \mathrm{~h}$. It was obtained $3.01 \mathrm{~g}$ of SP 4. Anal. found: C 5.89, H 1.25, N $2.41 \%$. As calculated on C \%, $1.0 \mathrm{~g}$ of CSP contains $0.26 \mathrm{mmol}$ of bound organic material.

\section{SP 5}

The mixture of 1,3-dichloro-4,6-dinitrobenzene (0.71 g; $3.00 \mathrm{mmol})$, silica gel Separon SGX $\mathrm{NH} 2(3.0 \mathrm{~g})$ and $\mathrm{N}, \mathrm{N}$-dimethylformamide $(15 \mathrm{ml})$ was sonificated for $5 \mathrm{~min}$ and than stirred at room temperature for $24 \mathrm{~h}$. The obtained modified silica gel was isolated by vacuum filtration on G-4 filter and washed subsequently with $N, N$-dimethylformamide $(50 \mathrm{ml})$ and dichloromethane $(50 \mathrm{ml})$. After drying at $70{ }^{\circ} \mathrm{C}$ for $5 \mathrm{~h}$ it was obtained $3.32 \mathrm{~g}$ of SP 5. Anal. found: C $6.20, \mathrm{H}$ $1.05, \mathrm{~N} 2.41 \%$. As calculated on $\mathrm{C} \%, 1.0 \mathrm{~g}$ of CSP contains $0.52 \mathrm{mmol}$ of bound organic material.

\section{SP 6}

The mixture of SP $5(3.0 \mathrm{~g})$, 1,2-diaminoethane $(10 \mathrm{ml})$ and dichloromethane $(10 \mathrm{ml})$ was homogenized by sonification for $5 \mathrm{~min}$. The obtained suspension was stirred for $2 \mathrm{~h}$ at room temperature. Product was isolated by vacuum filtration on G-4 filter, washed with methanol (100 $\mathrm{ml}$ ) and dried at $70{ }^{\circ} \mathrm{C}$ for $5 \mathrm{~h}$. It was obtained $2.99 \mathrm{~g}$ of SP 6. Anal. found: C 7.16, H 1.38, N $3.70 \%$. As calculated on C \%, $1.0 \mathrm{~g}$ of CSP contains $0.49 \mathrm{mmol}$ of bound organic material.

\section{SP 7}

The mixture of 2,3,5,6-tetrachloro-[1,4]-benzoquinone (0.70 g; $3.00 \mathrm{mmol})$, silica gel Separon SGX NH2 $(3.0 \mathrm{~g})$ and $N, N$-dimethylformamide $(15 \mathrm{ml})$ was sonificated for $5 \mathrm{~min}$ and than stirred at room temperature for $24 \mathrm{~h}$. The obtained modified silica gel was isolated by vacuum filtration on G-4 filter and washed subsequently with $N, N$-dimethylformamide $(50 \mathrm{ml})$ and dichloromethane $(50 \mathrm{ml})$. After drying at $70{ }^{\circ} \mathrm{C}$ for $5 \mathrm{~h}$ it was obtained $3.20 \mathrm{~g}$ of SP 7. Anal. 
found: C 4.76, H 0.93, N $0.97 \%$. As calculated on C \%, $1.0 \mathrm{~g}$ of CSP contains $0.32 \mathrm{mmol}$ of bound organic material.

\section{SP 8}

The mixture of SP 7 (3.0 g), 1,2-diaminoethane $(10 \mathrm{ml})$ and dichloromethane $(10 \mathrm{ml})$ was homogenized by sonification for $5 \mathrm{~min}$. The obtained suspension was stirred for $2 \mathrm{~h}$ at room temperature. Product was isolated by vacuum filtration on G-4 filter, washed with methanol (100 $\mathrm{ml}$ ) and dried at $70{ }^{\circ} \mathrm{C}$ for $5 \mathrm{~h}$. It was obtained $3.04 \mathrm{~g}$ of SP 8. Anal. found: C 5.63, H 1.16, N $1.88 \%$. As calculated on $\mathrm{C} \%, 1.0 \mathrm{~g}$ of CSP contains $0.33 \mathrm{mmol}$ of bound organic material.

\section{Preparation of chiral stationary phases CSP 1 - CSP 14}

\section{General procedure for preparation of chiral stationary phases}

The mixture of starting substances was homogenized by treatment in ultrasonic bath for 5 min. After that the suspension was stirred at room temperature overnight and product, obtained in the form of yellow powder, isolated by vacuum filtration on G-4 filter, washed with methanol (100 $\mathrm{ml})$ and dried at $70{ }^{\circ} \mathrm{C}$ for $5 \mathrm{~h}$.

Synthesis of CSP 1 - CSP 3 and CSP 7 was published previously. ${ }^{7,34}$

\section{CSP 4}

Prepared from SP 2 (2.00 g), $N$-(3,5-dinitrobenzoyl)-L-phenylalanine (0.71 g. $2.0 \mathrm{mmol})$ and EEDQ $(0.49 \mathrm{~g}, 2.0 \mathrm{mmol})$ in anhydrous THF $(10 \mathrm{ml})$. It was obtained $2.25 \mathrm{~g}$ of CSP 4. Anal. found: $\mathrm{C} 8.76, \mathrm{H} 1.33, \mathrm{~N} 3.01 \%$. As calculated on C \%, $1.0 \mathrm{~g}$ of CSP contains $0.22 \mathrm{mmol}$ of bound selector.

\section{CSP 5}

Prepared from SP 2 (2.00 g), $N$-acetyl-L-phenylglycine $(0.38 \mathrm{~g} ; 2.0 \mathrm{mmol})$ and EEDQ $(0.49 \mathrm{~g}$, $2.0 \mathrm{mmol})$ in anhydrous THF $(10 \mathrm{ml})$. It was obtained $2.19 \mathrm{~g}$ of CSP 5. Anal. found: $\mathrm{C} 7.48, \mathrm{H}$ $1.33, \mathrm{~N} 2.50 \%$. As calculated on C \%, $1.0 \mathrm{~g}$ of CSP contains $0.22 \mathrm{mmol}$ of bound selector.

\section{CSP 6}

Prepared from SP 2 (2.00 g), $N$-pivaloyl-L-phenylglycine $(0.47 \mathrm{~g} ; 2.0 \mathrm{mmol})$ and EEDQ (0.49 g, $2.0 \mathrm{mmol})$ in anhydrous THF $(10 \mathrm{ml})$. It was obtained $2.19 \mathrm{~g}$ of CSP 6. Anal. found: C $8.01, \mathrm{H}$ 1.42 , N $2.44 \%$. As calculated on C \%, $1.0 \mathrm{~g}$ of CSP contains $0.21 \mathrm{mmol}$ of bound selector.

\section{CSP 8}

Prepared from SP 1 (2.00 g), $N$-naphthoyl-L-phenylglycine (0.61 g; $2.0 \mathrm{mmol})$ and EEDQ (0.49 $\mathrm{g}, 2.0 \mathrm{mmol})$ in anhydrous THF (10 ml). It was obtained $2.19 \mathrm{~g}$ of CSP 8. Anal. found: C 10.19, $\mathrm{H} 1.46, \mathrm{~N} 2.57 \%$. As calculated on C \%, $1.0 \mathrm{~g}$ of CSP contains $0.23 \mathrm{mmol}$ of bound selector.

\section{CSP 9}

Prepared from SP 4 (2.00 g), $N$-(3,5-dinitrobenzoyl)-L-phenylglycine (0.69 g. $2.0 \mathrm{mmol})$ and EEDQ $(0.49 \mathrm{~g}, 2.0 \mathrm{mmol})$ in anhydrous THF $(10 \mathrm{ml})$. It was obtained $2.18 \mathrm{~g}$ of CSP 9. Anal. found: $\mathrm{C} 9.32, \mathrm{H} 1.35, \mathrm{~N} 3.13 \%$. As calculated on C \%, $1.0 \mathrm{~g}$ of CSP contains $0.22 \mathrm{mmol}$ of bound selector. 


\section{CSP 10}

Prepared from SP 3 (2.00 g), $N$-(3,5-dinitrobenzoyl)-L-phenylglycine (0.69 g. $2.0 \mathrm{mmol})$ and EEDQ $(0.49 \mathrm{~g}, 2.0 \mathrm{mmol})$ in anhydrous THF $(10 \mathrm{ml})$. It was obtained $2.24 \mathrm{~g}$ of CSP 10. Anal. found: C 9.95, H 1.44, N $3.30 \%$. As calculated on C \%, $1.0 \mathrm{~g}$ of CSP contains $0.24 \mathrm{mmol}$ of bound selector.

\section{CSP 11}

Prepared from SP 1 (2.00 g), (R)-(+)-2-amino- $N$-(1-naphthalen-1-yl-ethyl)-acetamide (0.45 g, $2.0 \mathrm{mmol}$ ) and $N$-ethyldiisopropylamine (Hünig base, $0.35 \mathrm{ml}, 2.0 \mathrm{mmol}$ ) in anhydrous THF (10 $\mathrm{ml}$ ). It was obtained $2.19 \mathrm{~g}$ of CSP 11. Anal. found: C 8.51, H 1.32, N $2.30 \%$. As calculated on $\mathrm{C} \%, 1.0 \mathrm{~g}$ of CSP contains $0.24 \mathrm{mmol}$ of bound selector.

\section{CSP 12}

Prepared from SP 2 (2.00 g), (S)-(+)-6-methoxy-2-naphthyl-propionic acid (0.46 g; $2.0 \mathrm{mmol})$ and EEDQ $(0.49 \mathrm{~g}, 2.0 \mathrm{mmol})$ in anhydrous THF $(10 \mathrm{ml})$. It was obtained $2.19 \mathrm{~g}$ of CSP 12. Anal. found: C 8.81, H 1.45, N $2.24 \%$. As calculated on C \%, $1.0 \mathrm{~g}$ of CSP contains $0.23 \mathrm{mmol}$ of bound selector.

\section{CSP 13}

Prepared from SP 6 (2.00 g), (S)-(+)-6-methoxy-2-naphthyl-propionic acid (0.46 g; $2.0 \mathrm{mmol})$ and EEDQ (0.49 g, $2.0 \mathrm{mmol})$ in anhydrous THF $(10 \mathrm{ml})$. It was obtained $2.20 \mathrm{~g}$ of CSP 13. Anal. found: C 8.53, H 1.41, N 2.24 \%. As calculated on C \%, $1.0 \mathrm{~g}$ of CSP contains $0.23 \mathrm{mmol}$ of bound selector.

\section{CSP 14}

Prepared from SP 8 (2.00 g), $(S)-(+)-6$-methoxy-2-naphthyl-propionic acid (0.46 g; $2.0 \mathrm{mmol})$ and EEDQ (0.49 g, $2.0 \mathrm{mmol})$ in anhydrous THF $(10 \mathrm{ml})$. It was obtained $2.19 \mathrm{~g}$ of CSP 14. Anal. found: C 8.00, H 1.32, N $1.54 \%$. As calculated on C \%, $1.0 \mathrm{~g}$ of CSP contains $0.21 \mathrm{mmol}$ of bound selector.

\section{Acknowledgements}

The authors acknowledge the support by Ministry of Science, Education and Sport of Republic Croatia (Project 098-0982904-2910).

\section{References}

1. Noyori, R. Asymmetric Catalysis in Organic Synthesis; J. Wiley \& Sons: New York, 1994.

2. Comprehensive Asymmetric Catalysis; Jacobsen, E. N.; Pfaltz, A.; Yamamoto, H. Eds.; Springer: New York, 1999.

3. Noyori, R. Angew. Chem. Int. Ed. 2002, 41, 2008.

4. Berthod, M.; Mignani, G.; Woodward, G.; Lemaire, M. Chem. Rev. 2005, 105, 1801. 
5. Berkessel, A.; Gröger, H. Asymmetric Organocatalysis; Wiley-VCH, 2005; pp 393-408.

6. Juza, M.; Mazzotti, M.; Morbidelli M. Trends Biotechnol. 2000, 18, 108.

7. Zafirova, B.; Landek, G.; Kontrec, D.; Šunjić, V.; Vinković, V. Croat. Chem. Acta 2004, 77, 573.

8. Kontrec, D.; Vinković, V.; Šunjić. V.; Mariotti, P.; Navarini, L. U.S. Patent 7,018,537 B2, 2006.

9. Kontrec, D.; Vinković, V.; Šepelj, M. Šunjić, V. Croat. Chem. Acta 2004, 77, 31.

10. Landek, G.; Vinković, M.; Kontrec, D.; Vinković, V. Chromatographia 2006, 64, 469.

11. Moslavac Forjan, D.; Kontrec, D.; Vinković, V. Chirality 2006, $18,857$.

12. Sekar, G; Nishiyama, H. J. Am. Chem. Soc. 2001, 123, 3603.

13. Nakamura, Y.; Takeuchi, S.; Zhang, S.; Okumura, K.; Ohgo, Y. Tetrahedron Lett. 2002, 43, 3053.

14. Gladiali, S.; Pulacchini, S.; Fabbri, D.; Manassero, M.; Sansoni, M. Tetrahedron Asymmetry 1998, 9, 391.

15. Gladiali, S.; Medici, S.; Kegl, T.; Kollar, L. Monatsh Chem. 2000, 131, 1351.

16. Cyr, P.W.; Rettig, S.J.; Patrick, B.O.; James, B.R. Organometallics 2002, 21, 4672.

17. Mori, M.; Nakanishi, M.; Kajishima, D.; Sato, Y. Org. Lett. 2001, 3, 1913.

18. Zhou, Y.-G.; Zhang, X. Chem. Commun. 2002, 1124.

19. Chapsal, B.D.; Hua, Z.; Ojima, I. Tetrahedron: Asymmetry 2006, 17, 642.

20. Kotani, S.; Hashimoto, S.; Nakajima, M. Tetrahedron 2007, 63, 3122.

21. Nakajima, M.; Kotani, S.; Ishizuka, T.; Hashimoto, S. Tetrahedron Lett. 2005, 46, 157.

22. Ogawa, C.; Sugiura, M.; Kobayashi, S. Angew. Chem. Int. Ed. 2004, 43, 6491.

23. Yagi, M.; Akutagawa, S. EU Patent 0118257 A1, 1986.

24. Wenzel, T. T.; Dixon, Z. D. U.S. Patent 7,196,032, 2007.

25. Huang, Y.-Y.; Deng, G.-J.; Wang, X.-Y.; He, Y.-M.; Fan, Q.-H. Chin. J. Chem. 2004, 22, 891.

26. Tokuoka, E.; Kotani, S.; Matsunaga, H.; Ishizuka, T.; Hashimoto, S.; Nakajima, M., Tetrahedron: Asymmetry 2005, 16, 2391.

27. Yi, X.-Y.; Williams, I.D.; Leung W.-H. J. Organomet. Chem. 2006, 691, 1315.

28. Mikami, K.; Yamaoka, M. Tetrahedron Lett. 1998, 39, 4501.

29. Welch, C. J. J. Chromatogr. A 1994, 666, 3.

30. Hyun, M. H.; Hwang, S.-R.; Han, S. C. Bull. Korean Chem. Soc. 1999, 20, 1309.

31. Kontrec, D.; Vinković, V.; Lesac, A.; Aced, A.; Šunjić, V. Enantiomer 2000, 5, 333.

32. Prelog, V. Chem. Brit. 1968, 4, 382.

33. Takaya, H.; Akutagawa, S.; Noyori, R. Org. Synth. 1993, Coll. Vol. 8, 57.

34. Moslavac Forjan, D.; Vinković, V.; Kontrec, D. Acta Chromatogr. 2006, 17, 97. 